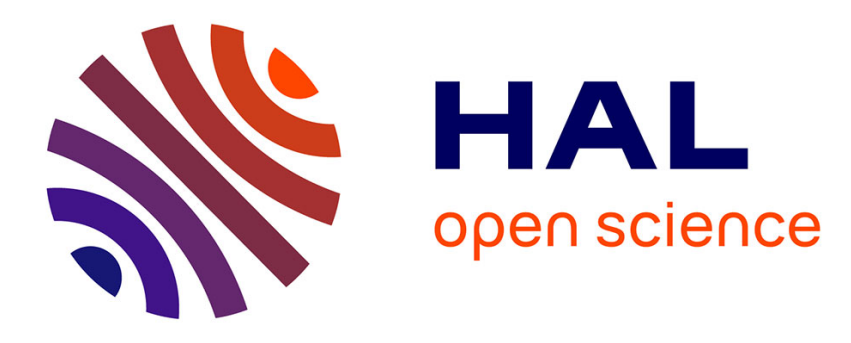

\title{
Optimal Redistributive Taxation in Credit Markets with Adverse Selection
}

\author{
Anastasios Dosis
}

\section{To cite this version:}

Anastasios Dosis. Optimal Redistributive Taxation in Credit Markets with Adverse Selection. 2019. hal-02130458

\section{HAL Id: hal-02130458 \\ https://essec.hal.science/hal-02130458}

Preprint submitted on 15 May 2019

HAL is a multi-disciplinary open access archive for the deposit and dissemination of scientific research documents, whether they are published or not. The documents may come from teaching and research institutions in France or abroad, or from public or private research centers.
L'archive ouverte pluridisciplinaire HAL, est destinée au dépôt et à la diffusion de documents scientifiques de niveau recherche, publiés ou non, émanant des établissements d'enseignement et de recherche français ou étrangers, des laboratoires publics ou privés. 


\section{ESS IC}

BUSINESS SCHOOL

\section{OPTIMAL REDISTRIBUTIVE TAXATION} IN CREDIT MARKETS WITH ADVERSE SELECTION

\section{RESEARCH CENTER}

ANASTASIOS DOSIS

ESSEC WORKING PAPER 1906

APRIL 2019

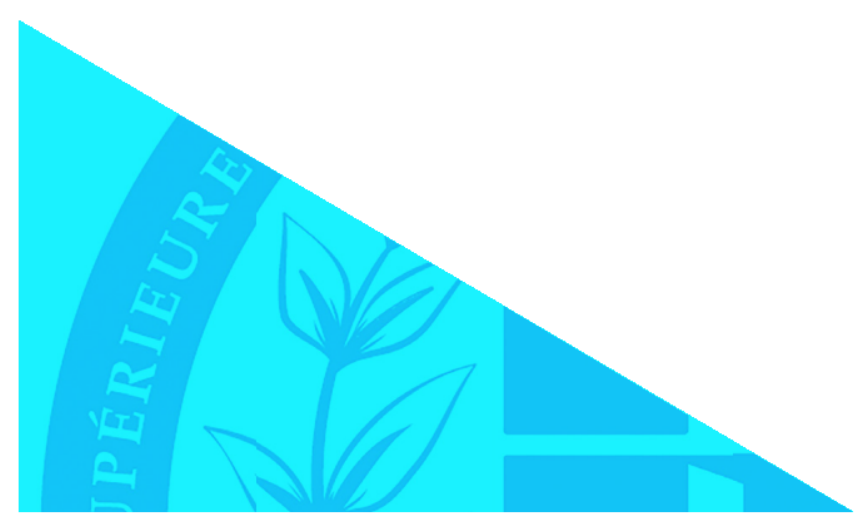




\title{
Optimal Redistributive Taxation in Credit Markets with Adverse Selection
}

\author{
Anastasios Dosis*
}

\begin{abstract}
I study optimal redistributive taxation in credit markets with adverse selection. Under symmetric information, the tax system is non-distortionary and unambiguously benefits high-risk types at the expense of low-risk types. Under asymmetric information, a range of taxes exists that creates Pareto improvements relative to the (zero-tax) market allocation by increasing aggregate investment. For sufficiently high taxes, an increase in the safe interest rate can be accompanied by an increase in investment.
\end{abstract}

JEL classification: $D 82, D 86, H 82, H 25$

Keywords: Credit market, adverse selection, taxation, redistribution, welfare

\section{INTRODUCTION}

It is well known that adverse selection causes inefficiencies in markets that frequently justify for public policy. For instance, during financial crises, governments attempt to increase liquidity through asset purchases or subsidies to firms in distress as was recently exemplified by the Troubled Asset Relief Program (TARP) signed in October 2008 which allowed the US governement to buy $\$ 700$ billion of troubled (or "toxic") assets to "rejuvenate" the market. ${ }^{1}$ Moreover, loan government-

${ }^{*}$ Department of Economics - ESSEC Business School and THEMA, 3 Av. Bernard Hirsch, B.P. - 50105, Cergy, 95021, France (dosis@essec.com). I am grateful to Motty Perry and Herakles Polemarchakis for their support and guidance. I also thank Theo Diasakos, Peter Hammond and Phil Reny for insightful comments that improved the paper and seminar participants at various theory seminars at the University of Warwick for useful comments. All the remaining errors are mine.

${ }^{1}$ See Tirole (2012), Philippon and Skreta (2012) and Philippon and Schnabl (2013) for more details. 
backed guarantee programmes are frequently implemented as a vehicle to facilitate access to credit for small enterprises and start-us. These programmes encourage banks to lend to entrepreneurs with no collateral or other pledgable assets by guaranteeing (partial) loan repayment even if an entrepreneur is unable to meet her obligations. The rationale underlying such schemes is that potential credit market frictions confine entrepreneurs with good ideas to entering the marketplace. $^{2}$ This paper studies the effectiveness of a simple tax-subsidy scheme that resembles a loan government-backed guarantee programme to boost investment and improve welfare in credit markets with adverse selection.

The market consists of a continuum of entrepreneurs with risky, variable investment projects that succeed or fail. A project (equivalently an entrepreneur) can be either high risk or low risk: low-risk projects yield a higher expected return than high-risk projects for the same amount of investment, although high-risk projects yield a higher ex post return in case of success. The market also consists of competitive banks that raise funds inelastically at an exogenously given safe interest rate and offer loan contracts that specify the level of the loan and the payments of an entrepreneur to the bank in every possible contingency. I show that under symmetric information, low-risk types borrow more than high-risk types and pay a lower (per unit of investment) interest rate; under asymmetric information, high-risk types invest efficiently, whereas low-risk types underinvest relative to the symmetric information benchmark.

I then examine the effect of a simple budget-balanced, tax-subsidy scheme on equilibrium investment and welfare. The tax-subsidy system is similar to that analysed in Wilson (1977), Dahlby (1981) and Crocker and Snow (1985a,b) in the stylised insurance market of Rothschild and Stiglitz (1976), and more recently in Ghatak, Morelli, and Sjöström (2007) and Scheuer (2013) in a credit market. ${ }^{3}$ Ev-

\footnotetext{
${ }^{2}$ See for instance OECD (2018) or the report of the OECD http://www.oecd.org/ global-relations/45324327.pdf for more details.

${ }^{3}$ Ghatak, Morelli, and Sjöström (2007) and Scheuer (2013) consider a model in which an indi-
} 
ery entrepreneur pays a specific tax in case she succeeds, which is redistributed as a lump-sum subsidy; the subsidy can be pledged as collateral in case an entrepreneur fails. I argue that an alternative interpretation of the tax-subsidy scheme is that of an entirely budget-balanced, loan government-backed guarantee programme.

Under symmetric information, the tax is non-distortionary and redistributes wealth from high-risk to low-risk types. Under asymmetric information, the possibility for entrepreneurs to pledge the subsidy as collateral alter the equilibrium contracts. Indeed, in the least-cost separating allocation, low-risk types use the entire subsidy as collateral. This allows them to increase leverage and ameliorate the cost of cross-subsidisation. I establish that taxes can lead to Pareto improvements relative to the zero-tax allocation by increasing aggregate investment. The scheme entails two countervailing effects to low-risk types. The negative effect is a consequence of cross-subsidisation; the positive effect is due to the relaxation of the incentive constraint of high-risk types that allows low-risk types to approach their symmetric information investment level. When the share of low-risk types is sufficiently high, the latter effect dominates and consequently low-risk types benefit from the tax system. Last, I study the effect of interest rate changes on aggregate investment and welfare. Perhaps the most surprising result is that for sufficiently high taxes, aggregate investment can be increasing in the interest rate.

Regarding the literature, related are the papers by Innes (1991) and Martin (2011), who study different type of policies in models similar to that studied in the present paper. Innes (1991) shows how the government can increase welfare by offering subsidised debt contracts. Martin (2011) shows that the government,

vidual selects between becoming a worker, and receiving the labour market wage, or becoming an entrepreneur, and borrowing from the credit market. The tax system aims to discourage individuals with low-quality projects from becoming entrepreneurs to "correct" for occupational choice by reducing adverse selection and hence improve efficiency. In this paper, I allow for variable investment projects as opposed to fixed-investment projects, which allows for separation of types. Moreover, the subsidy received by the government plays a fundamental role in this paper since it is necessary for entrepreneurs to pledge this as collateral. 
by establishing a new market in which entrepreneurs can borrow without conditioning their loans, can attain Pareto efficiency. Unlike the present paper, they neither consider the effect of taxes on aggregate investment nor the combination of interest rate changes and taxation on investment and welfare.

The remainder of the paper is organised as follows: In Section 2, I describe the economy and the tax system; in Section 3, I study the symmetric information benchmark; in Section 4 I study the market under asymmetric information and the effect of taxation. In Section 4, I provide policy implications.

\section{THE ECONOMY}

- Entrepreneurs. There are two periods (period one and period two) and a single good that is used for consumption and investment. A continuum of entrepreneurs of mass one are each endowed with a project. There are two possible projects: highrisk and low-risk, $i=H, L$ and a set of measure $\lambda$ of entrepreneurs is endowed with low-risk projects. ${ }^{4}$ By investing $x$ units of the good in the project in period one, an entrepreneur can realise $z_{i} f(x)$ units with probability $\pi_{i}$ or zero units with probability $1-\pi_{i}$ in period two, where $z_{i}>0$ for every $i, f(0)=0, f^{\prime}(x)>0$, $f^{\prime \prime}(x)<0, \lim _{x \rightarrow 0} f^{\prime}(x)=\infty, \lim _{x \rightarrow \infty} f^{\prime}(x)=0$, and $\pi_{L}>\pi_{H} .{ }^{5}$ Uncertainty is purely idiosyncratic. I further assume that

$$
z_{H}>z_{L} \text { and } \pi_{H} z_{H} \leq \pi_{L} z_{L}
$$

Hence, conditional on success and for the same amount of investment, the highrisk project returns a higher output than the low-risk project. Nonetheless, the low-risk project has a higher expected return than the hnigh-risk project. Note that when the two projects have the same expected return, the high-risk project is a mean-preserving spread of the low-risk project; when the expected return of

\footnotetext{
${ }^{4}$ For simplicity, I refer to an entrepreneur with a low-risk (high-risk) project as a "low-risk" ("high-risk") type.

${ }^{5}$ Inada's conditions are sufficient to guarantee interior solutions and, hence, considerably simplify the analysis but are not necessary for any of the results.
} 
the low-risk project is strictly higher than that of the high-risk project, the low-risk project second-order stochastically dominates the high-risk project. Although this assumption is very common in the credit rationing literature, none of the results rely on it as I argue at the end of the paper. ${ }^{6}$

Let

$$
\pi^{p}=\lambda \pi_{L}+(1-\lambda) \pi_{H}
$$

denote the population's "average probability of success". I assume that only the individual state is observable by outsiders and verifiable by a court of law. This assumption rules out equity as a feasible loan contract. Equivalently, it rules out linear or non linear taxes (see below for more details). Last, I assume that entrepreneurs have no wealth, are risk neutral and do not discount the future.

Banks. There are at least two profit-maximising banks in the economy that raise deposits inelastically in period one at a (net) risk-free interest rate equal to $r$. Entrepreneurs apply for a loan contract $(x, c) \in \mathbb{R}_{+}^{2}$ to banks, where $x$ denotes the amount of loan (henceforth, the loan) and $c$ denotes the transfer from the entrepreneur to the bank in case the project fails (henceforth, the collateral). I assume that entrepreneurs are protected by limited liability. Following an application, banks compete in the interest rate they charge denoted by $\rho$. The market takes the form of a signalling game as is extensively analysed in Dosis (2019).

The Tax System. Let $t$ denote the net specific tax an entrepreneur pays in case her project succeeds and $T$ the subsidy she receives. The tax system is ex post budget balanced, which means that the government simply redistributes wealth. Moreover, the tax system is non-discriminatory (or anonymous) in the sense that every type pays the same specific tax and receives the same lump-sum subsidy regardless of her contract choice. This assumption fits well in environments in

\footnotetext{
${ }^{6}$ The assumption of mean-preserving spreads was first imposed in the seminal work of Stiglitz and Weiss (1981).
} 
which the government is unable to observe the entrepreneurs' contract choices. Suppose that the tax-subsidy scheme be given by $(t, T)$; following the discussion above, this satisfies the following condition:

$$
T=\frac{\pi^{p}}{1-\pi^{p}} t
$$

Because $T$ is uniquely identified for every $t$, it suffices to solely specify $t .^{7}$

An alternative, perhaps interesting, interpretation of the tax system is to consider this as a budget-balanced loan government-backed guarantee programme. According to this interpretation, entrepreneurs voluntarily decide to participate in a scheme in which the government guarantees part of the losses of a loan undertaken if the entrepreneur is unable to fulfil her obligations. As a return, an entrepreneur pays a fixed fee, which is equivalent to the specific tax specified above. Loan government-backed guarantee programmes constitute one of the most widespread public policies to encourage entrepreneurship. The objective of these programmes is to encourage banks to lend to small firms that might lack collateral or other pledgable assets. Variations of loan government-backed guarantee programmes are implemented in USA, the UK, France, Germany and many other countries. The basic principles of loan government-backed guarantee programmes are similar in all countries: the government undertakes any losses that cannot be met by borrowers; borrowers pay an arrangement fee plus a small premium over the market rate.

The main discrepancy between the policy studied in this paper relative to the loan government-backed guarantee programmes that are implemented in practice is that the policy in this paper is entirely budget balanced whilst loan governmentbacked guarantee programmes are mainly publicly funded.

\footnotetext{
${ }^{7}$ Evidently, the tax system specified above is unrealistic in many respects. Most notably, in reality, entrepreneurs do not pay specific, i.e., regardless of their income, but likely linear or nonlinear taxes. Note, however, that given that the only observable and contractible variable is the individual state (i.e., success or failure), the government faces the constraints that banks face; given that equity is not feasible, taxes that condition payments on earned profits are not feasible either.
} 
Feasible Contracts. One implicit assumption is that an entrepreneur is taxed if and only if she undertakes the venture. Because entrepreneurs are protected by limited liability, I restrict attention to taxes and loan contracts that satisfy a set of feasibility constraints

$$
z_{i} f(x)-\rho-t \geq 0, \quad c \leq \frac{\pi^{p}}{1-\pi^{p}} t
$$

It is perhaps more convenient to study the equilibria of the game by defining allocations. An allocation is a pair of contracts, $\left(\left(x_{i}, \rho_{i}, c_{i}\right)\right)_{i}$, one for each type of entrepreneur.

\section{SYMMETRIC INFORMATION BENCHMARK}

- Zero-Tax Equilibria. Under symmetric information, competition in the banking sector ensures that entrepreneurs pay actuarially-fair interest rates and hence banks earn zero profits in equilibrium. The following lemma summarises the unique equilibrium under symmetric information.

Lemma 1. Under zero taxation and symmetric information, the equilibrium allocation is given by $\left(\left(x_{L}^{*}, \rho_{L}^{*}, 0\right),\left(x_{H}^{*}, \rho_{H}^{*}, 0\right)\right)$, where for every $i, \pi_{i} \rho_{i}^{*}=x_{i}^{*}$, and

$$
f^{\prime}\left(x_{i}^{*}\right)=\frac{1+r}{\pi_{i} z_{i}}
$$

The symmetric information equilibrium allocation is depicted in Figure 1a. The horizontal axis represents the loan (i.e., $x$ ) and the vertical axis represents the repayment (i.e., $\rho$ ). The two lines that pass through the origin (i.e., $Z P_{L}$ and $Z P_{H}$ ) represent the zero-profit lines of the banks for the low-risk and high-risk type respectively; the two curves (i.e., $\bar{I}_{L}$ and $\bar{I}_{H}$ ) represent the indifference curves of the low-risk and high-risk type respectively.

The equilibrium (expected) payoff of type $i$ is

$$
U_{i}^{*}=\pi_{i} z_{i} f\left(x_{i}^{*}\right)-x_{i}^{*}(1+r)
$$


- The Effect of Taxation. Consider now a strictly positive tax. Evidently, because the tax is specific, it does not distort the equilibrium levels of investment. The equilibrium payoff of type $i$ as a function of the tax is

$$
U_{i}^{*}(t)=\pi_{i} z_{i} f\left(x_{i}^{*}\right)-x_{i}^{*}(1+r)+\left(\left(1-\pi_{i}\right) \frac{\pi^{p}}{1-\pi^{p}}-\pi_{i}\right) t
$$

Given that $\pi_{H}<\pi^{p}<\pi_{H}$, the payoff of the high-risk type is strictly increasing in $t$ whilst the payoff of the low-risk type is strictly decreasing in $t$; the high-risk is simply cross-subsidized by the low-risk type through the tax-subsidy scheme.

\section{ASYMMETRIC INFORMATION}

Zero-Tax Equilibria. As shown in Dosis (2019), the equilibrium allocation is the least-cost separating allocation (LCS). As is well known, in the LCS allocation, highrisk types face no distortion relative to the symmetric information equilibrium; low-risk types' loan is distorted such that it is no more desired by high-risk types. Let

$$
\bar{\rho}_{L}=\frac{x(1+r)}{\pi_{L}}
$$

then, the low-risk type's level of investment $\bar{x}_{L}$ in the LCS allocation is the [lowrisk type's] payoff-maximising solution to the following equation:

$$
z_{H} f\left(x_{H}^{*}\right)-\frac{x_{H}^{*}(1+r)}{\pi_{H}}=z_{H} f(x)-\frac{x(1+r)}{\pi_{L}},
$$

which represents the binding incentive constraint of the high-risk type. Dosis (2019) shows that this equation has two solutions and the solution that maximises the payoff of the low-risk type is such that $\bar{x}_{L}<x_{H}^{*}$ : in the LCS allocation, the low-risk type is restricted by the incentive constraint and unable to raise as much capital as she would raise under symmetric information. The LCS allocation is depicted in Figure 1b.

Lemma 2. Under zero taxation and asymmetric information, the equilibrium allocation is given by $\left(\left(\bar{x}_{L}, \bar{\rho}_{L}, 0\right),\left(x_{L}^{*}, \rho_{L}^{*}, 0\right)\right)$. 


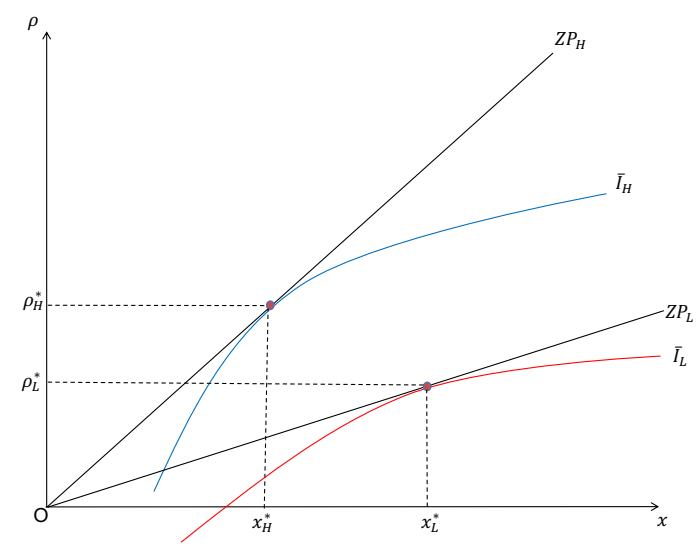

(a)

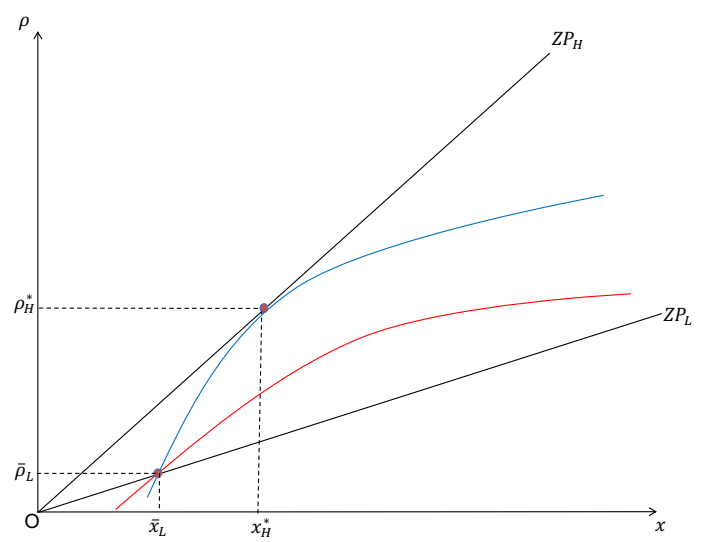

(b)

Figure 1: Panel (a) depicts the symmetric information equilibrium allocation; Panel (b) depicts the LCS allocation.

The equilibrium payoff of the high-risk type in the LCS is equal to her equilibrium payoff under symmetric information given in (2); the equilibrium payoff of the low-risk type is denoted for notational convenience by

$$
\bar{U}_{L}=\pi_{L} z_{L} f\left(\bar{x}_{L}\right)-\bar{x}_{L}(1+r)
$$

Implicit differentiation of (4) leads to

$$
\frac{d \bar{x}_{L}}{d r}=\frac{\bar{x}_{L} / \pi_{L}-x_{H}^{*} / \pi_{H}}{z_{H} f^{\prime}\left(\bar{x}_{L}\right)-(1+r) / \pi_{L}},
$$

which is strictly negative because $\bar{x}_{L} / \pi_{L}<x_{H}^{*} / \pi_{H}$; whereas, differentiation of (5) leads to

$$
d \bar{U}_{L} / d r=\underbrace{\left(\pi_{L} z_{L} f^{\prime}\left(\bar{x}_{L}\right)-(1+r)\right) d \bar{x}_{L} / d r}_{\text {Indirect effect }}-\underbrace{\bar{x}_{L}}_{\text {Direct effect }},
$$

which is also strictly negative because both the direct and indirect effects are negative.

Positive-Tax Equilibria. I proceed with a series of results that fully characterise the effect of taxation on the equilibrium allocation. 
Proposition 1. Under asymmetric information and for a sufficiently low t, the equilibrium allocation is given by $\left(\left(\bar{x}_{L}(t), \bar{\rho}_{L}(t), \frac{\pi^{p}}{1-\pi^{p}} t\right),\left(x_{H}^{*}, \bar{\rho}_{H}(t), \bar{c}_{H}(t)\right)\right)$, where

$$
\begin{gathered}
\pi_{H} \bar{\rho}_{H}(t)+\left(1-\pi_{H}\right) \bar{c}_{H}(t)=x_{H}^{*}(1+r) \\
\pi_{L} \bar{\rho}_{L}(t)+\left(1-\pi_{L}\right) \frac{\pi^{p}}{1-\pi^{p}} t=\bar{x}_{L}(t)(1+r) \\
z_{H} f\left(\bar{x}_{L}(t)\right)-\frac{\bar{x}_{L}(t)(1+r)}{\pi_{L}}=\left(z_{H} f\left(x_{H}^{*}\right)-\frac{x_{H}^{*}(1+r)}{\pi_{H}}\right)+\left(\frac{\left(1-\pi_{H}\right)}{\pi_{H}}-\frac{\left(1-\pi_{L}\right)}{\pi_{L}}\right) \frac{\pi^{p}}{1-\pi^{p}} t
\end{gathered}
$$

and

$$
\bar{c}_{H}(t) \leq \frac{\pi^{p}}{1-\pi^{p}} t
$$

Proposition 1 states that the low-risk type uses the entire subsidy as collateral. Note however, that this does not necessarily mean that her payoff is higher after taxation than before taxation. All Proposition 1 states is that in a specified interval of taxes, the low-risk type strictly prefers using the subsidy as collateral to borrow more rather than consuming it.

The following lemma summarises the behaviour of the investment of the lowrisk type as a function of the tax.

Lemma 3. $\bar{x}_{L}(t)$ is strictly increasing, continously differentiable and convex in $t$.

The payoff of the low-risk type in the equilibrium allocation as a function of the tax is written, for notational convenience, as

$$
\bar{U}_{L}(t)=\pi_{L} z_{L} f\left(x_{L}(t)\right)-x_{L}(t)(1+r)+\left(\left(1-\pi_{L}\right) \frac{\pi^{p}}{1-\pi^{p}}-\pi_{L}\right) t
$$

Given that the production function is strictly concave, $\bar{U}_{L}(t)$ is also strictly concave in $t$; this is the first part proven in Proposition 2. The question of interest then boils down to whether $\bar{U}_{L}(t)$ has an interior maximum. Proposition 2 states that there is indeed a threshold in the average probability of success $\pi_{L m i n}^{p}$, such 
that, for any $\pi^{p} \geq \pi_{L m i n}^{p}, U_{L}(t)$ has an interior maximum. The strict concavity of $\bar{U}_{L}(t)$ implies that there is a closed interval of taxes that increase the payoff of the low-risk type after taxation. Proposition 2 formalizes the discussion above.

Proposition 2. $\bar{U}_{L}(t)$ is concave in $t$ and for every $\pi^{p} \in\left[\pi_{L m i n}^{p}, \pi_{L}\right]$ attains a unique interior maximum.

Taxes and Interest Rate Changes. One interesting question is to examine the effect of interest rate changes on investment and welfare for a given tax. One can find the impact of an interest rate change on investment by implicitly differentiating (6)

$$
\frac{d \bar{x}_{L}(t)}{d r}=\frac{\bar{x}_{L}(t) / \pi_{L}-x_{H}^{*} / \pi_{H}}{z_{H} f^{\prime}\left(\bar{x}_{L}(t)\right)-(1+r) / \pi_{L}},
$$

Because the low-risk type might invest more than the high-risk type-contrary to the separating equilibrium under zero tax- an increase in the interest rate might be accompanied by an increase in the investment of the low-risk type. Because $\bar{x}_{L}(t)$ is strictly increasing in $t$, this is more prevalent for high taxes. This result is formally stated below.

Proposition 3. Suppose that $\bar{x}_{L}(t)>\pi_{L} x_{H}^{*} / \pi_{H}$; then, an increase in the interest rate will cause an increase in investment by low-risk types. If the increase in investment by low-risk types offsets the decrease in investment by high-risk types, then an increase in the interest rate will cause an increase in aggregate investment.

Consider now the impact of an interest rate change on the payoff of the low-risk type. For a given tax, differentiating (7) with respect to $r$, one obtains

$$
d \bar{U}_{L}(t) / d r=\underbrace{\left(\pi_{L} z_{L} f^{\prime}\left(\bar{x}_{L}(t)\right)-(1+r)\right) d \bar{x}_{L}(t) / d r}_{\text {Indirect effect }}-\underbrace{\bar{x}_{L}(t)}_{\text {Direct effect }},
$$

The direct effect is negative for every tax; the indirect effect is positive if $\bar{x}_{L}(t)>$ $\pi_{L} x_{H}^{*} / \pi_{H}$ and negative otherwise as explained above. Nonetheless, because $\bar{x}_{L}(t)$ is strictly increasing in $t$ it is rather unclear whether the positive indirect effect can ever offset the negative direct effect. 


\section{CONCLUDING REMARKS}

At least two policy implications emerge from the analysis. First, taxes create Pareto improvements if and only if the share of high-quality projects in the market is relatively high. If one accepts that during booms, high-quality projects outnumber low-quality projects, then an implication of the model is that Pareto improvements might only be possible during booms. During busts, the government might be unable to increase welfare, and hence, it might be optimal to decrease taxes. Second, Pareto improvements are feasible only if entrepreneurs can pledge government subsidies as collateral. An implication of this is that when collateral is scarce, the government can stimulate the economy by redistributing wealth.

\section{APPENDIX}

- Proof of Lemma 1. First, note that in an equilibrium under symmetric information, banks earn zero profits due to competition. Each contract maximises the payoff of the type that has been designed for; hence, the loan of type $i$ is characterised as the solution to the following programme:

$$
\max _{x} \pi_{i} z_{i} f(x)-x(1+r)
$$

Lemma 4. There exists $x_{i}^{*} \in(0, \infty)$ such that $f^{\prime}\left(x_{i}^{*}\right)-\frac{1+r}{\pi_{i} z_{i}}=0$ and $\pi_{i} z_{i} f\left(x_{i}^{*}\right)-x_{i}^{*}(1+r)>$ 0.

Proof. Let $h_{i}(x)=\pi_{i} z_{i} f(x)-x(1+r)$. Because $f$ is continuously differentiable, $h_{i}$ is also continuously differentiable with $h_{i}^{\prime}(x)=\pi_{i} z_{i} f^{\prime}(x)-(1+r)$ and $h_{i}^{\prime \prime}(x)=$ $\pi_{i} z_{i} f^{\prime \prime}(x)$. Because $f^{\prime \prime}<0, h_{i}^{\prime \prime}<0$ and therefore $h_{i}$ is concave for every $i$. Note that $h_{i}^{\prime}$ is strictly decreasing and because of Inada's conditions $\lim _{x \rightarrow \infty} h_{i}^{\prime}(x)=-(1+$ $r)<0$ and $\lim _{x \rightarrow 0} h_{i}^{\prime}(x)=\infty$. Because $h_{i}^{\prime}$ is strictly decreasing, continuous and the limits are defined as above, from the intermediate value theorem, there exists $x_{i}^{*} \in(0, \infty)$ such that $h_{i}^{\prime}\left(x_{i}^{*}\right)=0$, which implies that $f^{\prime}\left(x^{*}\right)=\frac{1+r}{\pi_{i} z_{i}}$. Given that $h_{i}(0)=0$ and $h_{i}$ is concave $x_{i}^{*}$ is a global maximum with $h_{i}\left(x_{i}^{*}\right)>0$ 
Proof of Proposition 1. To specify the LCS pair of contracts for a sufficiently small $t$, one needs to solve the following recursive programme:

$$
\begin{gathered}
\max _{(x, \rho, c) \in \mathbb{R}_{+}^{3}} \pi_{H}\left(z_{H} f(x)-\rho-t\right)+\left(1-\pi_{H}\right)(T-c) \text { s.t. } \\
\pi_{H} \rho+\left(1-\pi_{H}\right) c \geq x(1+r) \\
\rho \leq z_{H} f(x)-t \\
c \leq T
\end{gathered}
$$

which has solution $\left(x^{*}, \bar{\rho}_{H}(t), \bar{c}_{H}(t)\right)$ as defined in Eq. (1), and,

$$
\begin{gathered}
\max _{(x, \rho, c) \in \mathbb{R}_{+}^{3}} \pi_{L}\left(z_{L} f(x)-\rho-t\right)+\left(1-\pi_{L}\right)(T-c) \text { s.t. } \\
\pi_{L} \rho+\left(1-\pi_{L}\right) c \geq x(1+r) \\
\pi_{H}\left(z_{H} f\left(x^{*}\right)-\bar{\rho}_{H}-t\right)+\left(1-\pi_{H}\right)\left(T-\bar{c}_{H}\right) \geq \pi_{H}\left(z_{H} f(x)-\rho-t\right)+\left(1-\pi_{H}\right)(T-c) \\
\rho \leq z_{L} f(x)-t \\
c \leq T
\end{gathered}
$$

The first and the second constraint are each binding at the optimum; combining these two constraints one obtains

$$
z_{H} f(x)-\frac{x(1+r)}{\pi_{L}}-\left(z_{H} f\left(x^{*}\right)-\frac{x^{*}(1+r)}{\pi_{H}}\right)-\left(\frac{1-\pi_{H}}{\pi_{H}}-\frac{1-\pi_{L}}{\pi_{L}}\right) c=0
$$

Given that $z_{H} f(x)-\frac{x(1+r)}{\pi_{L}}$ is strictly increasing in $\left[0, x_{L}^{*}\right]$ and $\left(\frac{1-\pi_{H}}{\pi_{H}}-\frac{1-\pi_{L}}{\pi_{L}}\right) c \geq 0$ for every $c \geq 0$, the smallest solution of Eq. (10) is strictly increasing in $c$.

The payoff of the low-risk type is

$$
U_{L}(x, \rho, c)=\pi_{L}\left(z_{L} f(x)-\frac{x(1+r)}{\pi_{L}}\right)+\frac{\pi^{p}-\pi_{L}}{1-\pi^{p}} t
$$

which is strictly increasing in $x \in\left[0, x^{*}\right]$; hence, at the optimum $c=T$. Q.E.D. 
Proof of Lemma 3. Denote as $\bar{x}_{L}(t)$ the smallest root of Eq. (10); $\bar{x}_{L}(t)$ defines a function $\bar{x}_{L}:\left[0, t^{*}\right] \rightarrow[0, \infty)$, where $\bar{x}_{L}\left(t^{*}\right)=x_{L}^{*}$. Let

$$
q=\left(\frac{\left(1-\pi_{H}\right)}{\pi_{H}}-\frac{\left(1-\pi_{L}\right)}{\pi_{L}}\right) \frac{\pi^{p}}{1-\pi^{p}}
$$

and

$$
\psi(x)=\frac{1}{q}\left(z_{H} f(x)-\frac{x(1+r)}{\pi_{L}}-\left(z_{H} f\left(x^{*}\right)-\frac{x^{*}(1+r)}{\pi_{H}}\right)\right)
$$

Eq. (10) is defined as $\psi(x)=t$. Since $\psi(x)$ is continuous, strictly increasing and twice differentiable, it is one-to-one and therefore invertible in the interval $\left[0, x_{L}^{*}\right)$. Denote the inverse function as $x=\psi^{-1}(t)$. The first and second derivatives of $\psi^{-1}$ are well defined in this interval and because $\psi(x)$ is strictly increasing and differentiable, $\psi^{-1}$ is also strictly increasing and differentiable with $\left(\psi^{-1}\right)^{\prime}(t)=\frac{1}{\psi^{\prime}(x)}>0$ because $\psi^{\prime}(x)>0$. Moreover, $\left(\psi^{-1}\right)^{\prime \prime}(t)=-\frac{\psi^{\prime \prime}(x)}{\left(\psi^{\prime}(x)\right)^{2}}>0$ and, given that $\psi(\cdot)$ is strictly increasing and concave, $\psi^{-1}(t)$ is convex. Q.E.D.

Proof of Proposition 2. Because $f(x)$ is continuous and the first and second derivatives exist and are continuous for any $x>0$, and $\bar{x}_{L}(t)$ is also continuous and differentiable in $t \in[0, \tilde{t}], \bar{U}_{L}(t)$ is also continuous and differentiable in $[0, \tilde{t}]$; then:

$$
\begin{aligned}
\bar{U}_{L}^{\prime}(t) & =\left(z_{L} f^{\prime}\left(\bar{x}_{L}(t)\right)-\frac{1+r}{\pi_{L}}\right) \times \bar{x}_{L}^{\prime}(t)+\left(\frac{1-\pi_{L}}{\pi_{L}} \frac{\pi^{p}}{1-\pi^{p}}-1\right) \\
& =\frac{z_{L} f^{\prime}\left(\bar{x}_{L}(t)\right)-\frac{1+r}{\pi_{L}}}{z_{H} f^{\prime}\left(\bar{x}_{L}(t)\right)-\frac{1+r}{\pi_{L}}} \times q+\left(\frac{1-\pi_{L}}{\pi_{L}} \frac{\pi^{p}}{1-\pi^{p}}-1\right)
\end{aligned}
$$

where $q$ is as in Eq. (11). I show that there exists $\pi_{L m i n}^{p}$, such that $U_{L}^{\prime}\left(\bar{t}_{L o p t}\right)=0$, for some $\bar{t}_{\text {Lopt }}>0$, for every $\pi^{p} \in\left[\pi_{L m i n}^{p}, \pi_{L}\right]$. Eq. (13) can be re-written as:

$$
\bar{U}_{L}^{\prime}(t)=\left[(1-\alpha(t)) \frac{1-\pi_{L}}{\pi_{L}}+\alpha(t) \frac{1-\pi_{H}}{\pi_{H}}\right] \frac{\pi^{p}}{1-\pi^{p}}-1
$$

where

$$
\alpha(t)=\frac{z_{L} f^{\prime}\left(\bar{x}_{L}(t)\right)-\frac{1+r}{\pi_{L}}}{z_{H} f^{\prime}\left(\bar{x}_{L}(t)\right)-\frac{1+r}{\pi_{L}}}
$$


Note that

$$
\bar{U}_{L}^{\prime}(0)=\left(z_{L} f^{\prime}\left(\bar{x}_{L}(0)\right)-\frac{1+r}{\pi_{L}}\right) \times \bar{x}_{L}^{\prime}(0)+\left(\frac{1-\pi_{L}}{\pi_{L}} \frac{\pi^{p}}{1-\pi^{p}}-1\right)
$$

where the first term is strictly positive from Lemma 3 and Lemma 4 and the second term is strictly negative given the maintained assumptions. Therefore, there exists $\pi_{L m i n}^{p}$ such that $\bar{U}_{L}^{\prime}(0)>0$ for $\pi^{p} \in\left[\pi_{L m i n}^{p}, \pi_{L}\right]$. Moreover,

$$
\bar{U}_{L}^{\prime}\left(t^{*}\right)=\left(\frac{1-\pi_{L}}{\pi_{L}} \frac{\pi^{p}}{1-\pi^{p}}-1\right)<0
$$

for every $\pi^{p} \in\left[\pi_{H}, \pi_{L}\right)$. By applying the intermediate value theorem for $\pi^{p} \in$ $\left[\pi_{\text {Lmin }}^{p}, \pi_{L}\right)$, there exists $\bar{t}_{\text {Lopt }}>0$ such that $\bar{U}_{L}^{\prime}\left(\bar{t}_{\text {Lopt }}\right)=0$, which, given that $\bar{U}_{L}^{\prime}(t)>0$

for every $t \in\left[0, \bar{t}_{\text {Lopt }}\right)$ and $U_{L}^{\prime}(t)<0$ for every $t \in\left[\bar{t}_{\text {Lopt }}, t^{*}\right]$, corresponds to a global maximum in $\left[0, t^{*}\right)$. Therefore, for $\pi^{p} \in\left[\pi_{L m i n}^{p}, \pi_{L}\right]$, there exists $\bar{t}_{\text {Lopt }}>0$ that maximizes the payoff of the low-risk type. Q.E.D.

\section{REFERENCES}

Crocker, Keith J., and Arthur Snow, "The efficiency of competitive equilibria in insurance markets with asymmetric information," Journal of Public Economics, 26 (1985a), 207-219.

—_, "A simple tax structure for competitive equilibrium and redistribution in insurance markets with asymmetric information," Southern Economic Journal, 51 (1985b), 1142-1150.

Dahlby, Ben G., "Adverse selection and Pareto improvements through compulsory insurance," Public Choice, 37 (1981), 547-558.

Dosis, Anastasios, "Signalling, Productivity and Investment," forthcoming at Journal of Institutional and Theoretical Economics, (2019).

Ghatak, Maitreesh, Massimo Morelli, and Tomas Sjöström, “Entrepreneurial talent, occupational choice, and trickle up policies," Journal of Economic Theory, 137 (2007), 27-48. 
Innes, Robert, "Investment and government intervention in credit markets when there is asymmetric information," Journal of Public Economics, 46 (1991), 347-381.

Martin, Alberto, "Adverse selection, credit, and efficiency: the case of the missing market," 2011.

OECD, Financing SMEs and Entrepreneurs 2018 (2018), available at: https://www. oecd-ilibrary.org/content/publication/fin_sme_ent-2018-en.

Philippon, Thomas, and Philipp Schnabl, "Efficient recapitalization," The Journal of Finance, 68 (2013), 1-42.

Philippon, Thomas, and Vasiliki Skreta, "Optimal interventions in markets with adverse selection," The American Economic Review, 102 (2012), 1-28.

Rothschild, Michael, and Joseph Stiglitz, "Equilibrium in Competitive Insurance Markets: An Essay on the Economics of Imperfect Information," The Quarterly Journal of Economics, 90 (1976), 629-649.

Scheuer, Florian, "Adverse selection in credit markets and regressive profit taxation," Journal of Economic Theory, 148 (2013), 1333-1360.

Stiglitz, Joseph, and Andrew Weiss, "Credit rationing in markets with imperfect information," American economic review, (1981), 393-410.

Tirole, Jean, “Overcoming adverse selection: How public intervention can restore market functioning," The American Economic Review, 102 (2012), 29-59.

Wilson, Charles, "A model of insurance markets with incomplete information," Journal of Economic theory, 16 (1977), 167-207. 
ESSEC Business School

3 avenue Bernard-Hirsch

CS 50105 Cergy

95021 Cergy-Pontoise Cedex

France

Tel. +33 (0)134433000

www.essec.edu

ESSEC Executive Education

CNIT BP 230

92053 Paris-La Défense

France

Tel. +33 (0)1 46924900

www.executive-education.essec.edu

CONTACT

Centre de Recherche Tel. + 33 (0)134433091

ESSEC Asia-Pacific

5 Nepal Park research.center@essec.fr

Singapore 139408

Tel. +65 68849780

www.essec.edu/asia

ESSEC | CPE Registration number 200511927D

Period of registration: 30 June 2017 - 29 June 2023

Committee of Private Education (CPE) is part of Skillsfuture Singapore (SSG)

\section{ESSEC Africa}

Plage des Nations - Golf City

Route de Kênitra - Sidi Bouknadel (Rabat-Salê)

Morocco

Tel. +212 (0)5 37824000

www.essec.edu 